\title{
ELASTIC AND ELECTROMAGNETIC WAVE MONITORING OF EARLY AGE TRC
}

NICOLAS OSPITIA PATIÑO

Dr. Ali Pourkazemi

Dr. Eleni Tsangouri

Prof. Dr. Johan Stiens

Prof. Dr. Dimitrios Aggelis

\section{(10 \& CONSTRUCTIONS}

\section{ASEC 2020}




\section{MATERIAL}

TEXTILE REINFORCED CEMENTITIOUS COMPOSITE

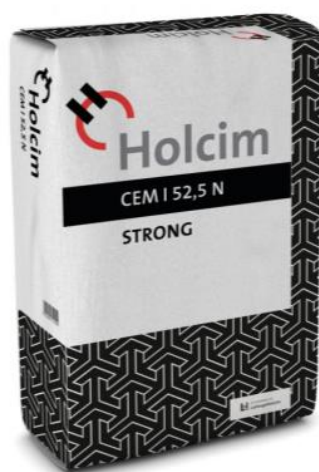

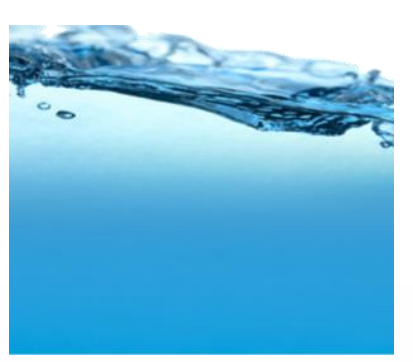
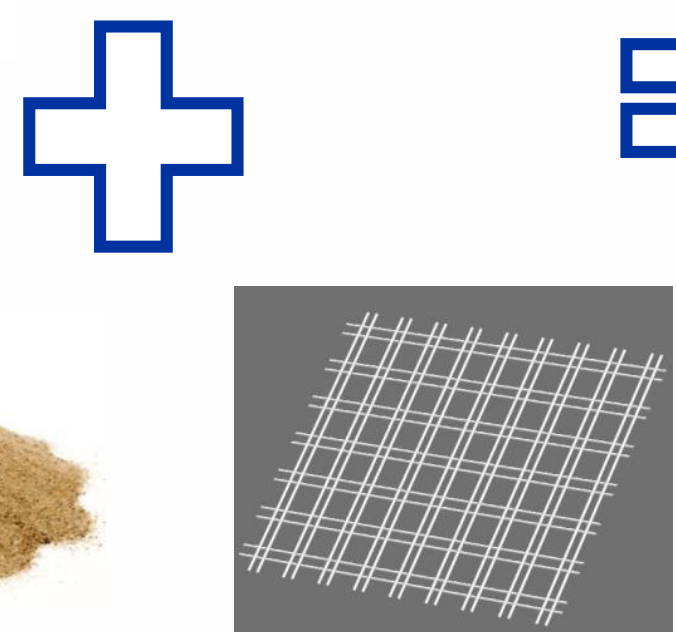

Durable

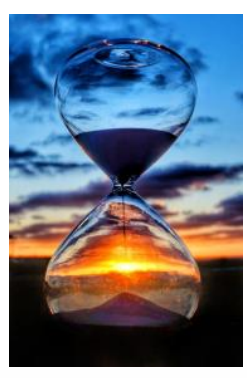

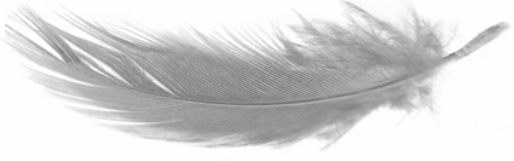

Lightweight

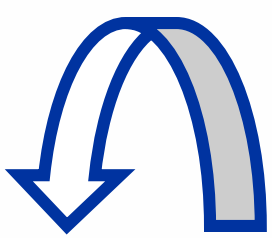

Freeform
1. "Heydar Aliyev Center / Zaha Hadid Architects" 14 Nov 2013. ArchDaily,
Accessed 26 Aug 2020. <https://www.archdaily.com/448774/heydar-aliyevcenter-zaha-hadid-architects> ISSN 0719-8884 
Monitor the hydration and curing of early age TRC with Ultrasound Pulse Velocity (UPV), Ultrasound Wave Reflection (UWR) and MMW Spectrometry to provide an assessment on the mechanical and physical changes during this period.

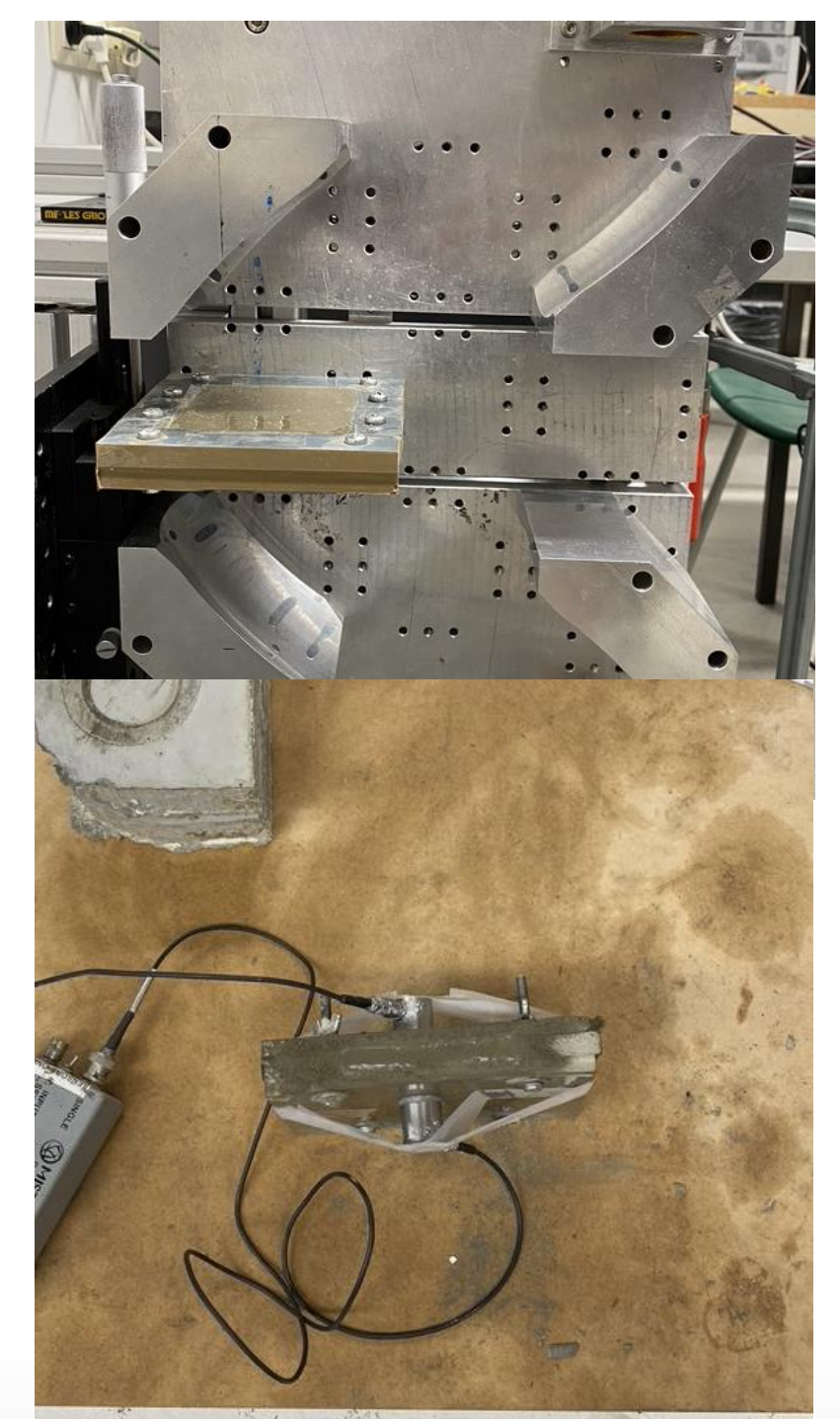




\section{Techniques and setup}

WB (IIIIM MECHANCSOF MATERALS




\section{ULTRASOUND}

Pulse Velocity

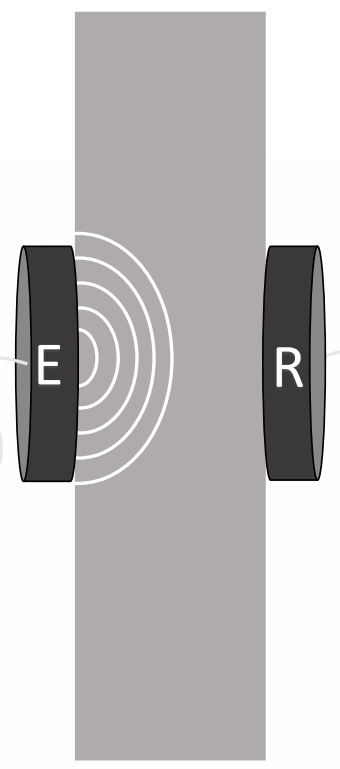

In order to monitor the development of stiffness in fresh mortar and TRC, the WAVE VELOCITY is measured experimentally and the Young Modulus is estimated.

\section{Wave Reflection}

In order to monitor the hydration of TRC plates, AMPLITUDE of the reflection longitudinal waves was continuously monitored.

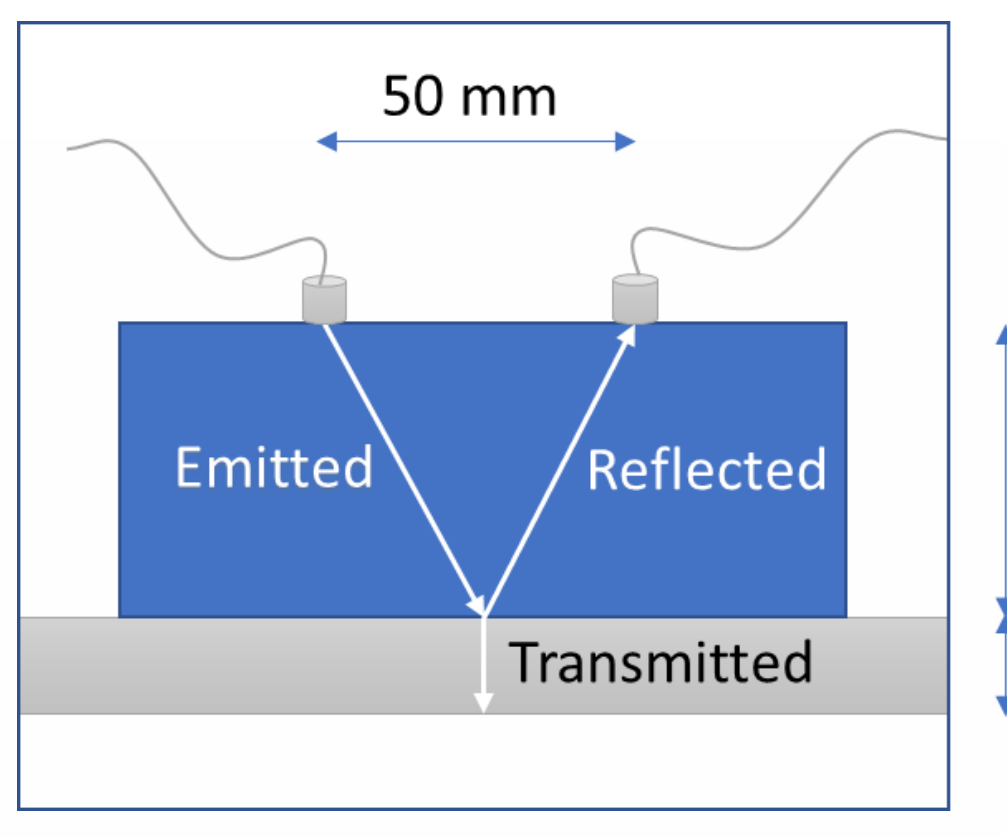

$50 \mathrm{~mm}$ 


\section{NON-DESTRUCTIVE TECHNIQUES}

\section{ULTRASOUND PULSE VELOCITY}

Pulse Velocity

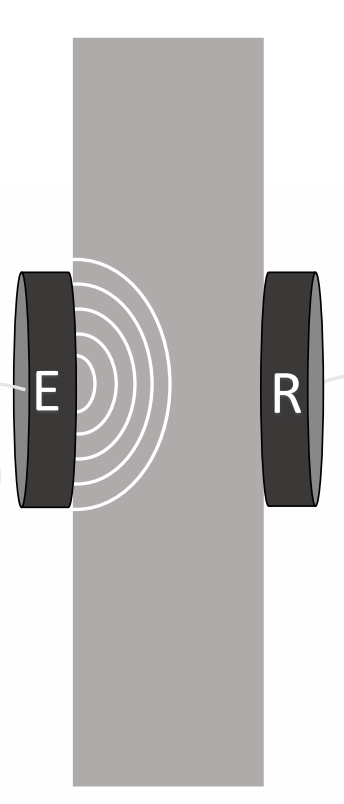

$$
V_{l}=\sqrt{\frac{E *(1-v)}{\rho(1+v)(1-2 v)}}
$$

- Micro-II Digital AE System

- R15 sensors

- Agilent $20 \mathrm{MHz}$ Waveform Generator
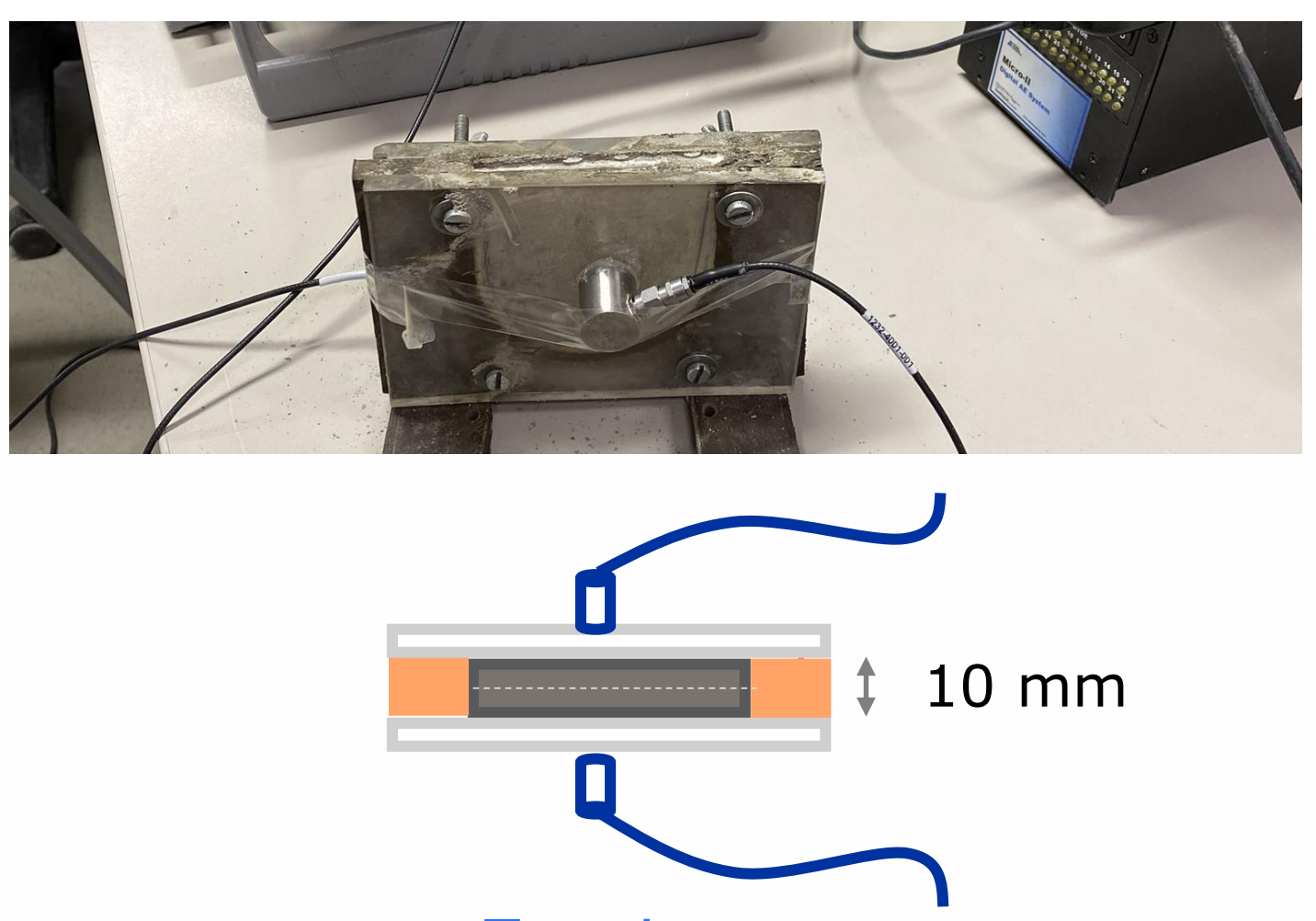

Top view 


\section{NON-DESTRUCTIVE TECHNIQUES}

\section{ULTRASOUND WAVE REFLECTION}

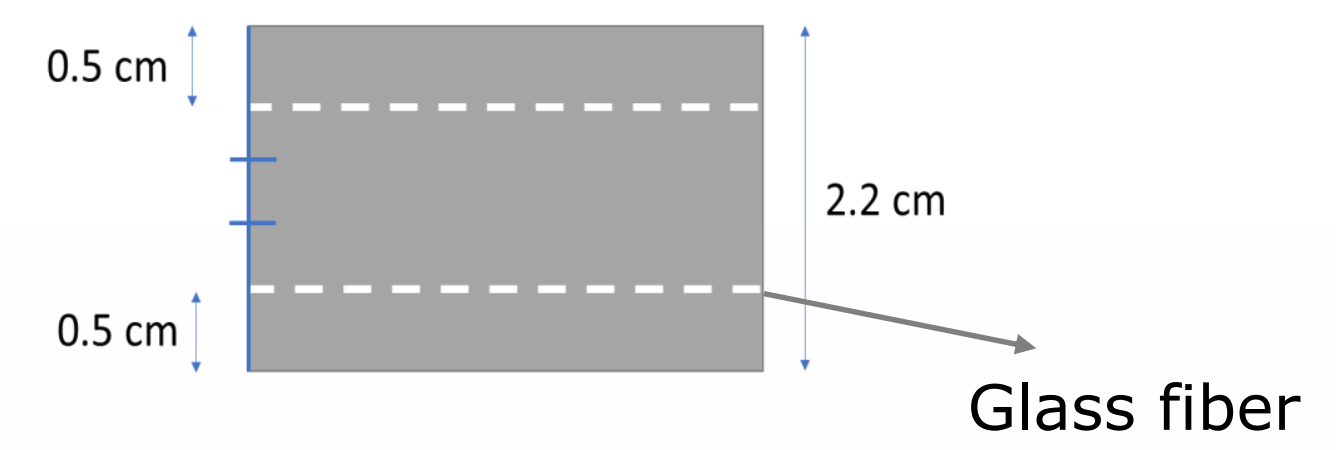

$$
r=\frac{A_{r}}{A_{i}}=\frac{\left(\rho_{\mathrm{trc}} V_{\mathrm{trc}}-\rho_{\mathrm{pvc}} V_{\mathrm{pvc}}\right)}{\rho_{\mathrm{trc}} V_{\mathrm{trc}}+\rho_{\mathrm{pvc}} V_{\mathrm{pvc}}}
$$

In order to monitor the hydration of TRC plates, AMPLITUDE of the reflection

\section{Wave Reflection} longitudinal waves was continuously monitored.

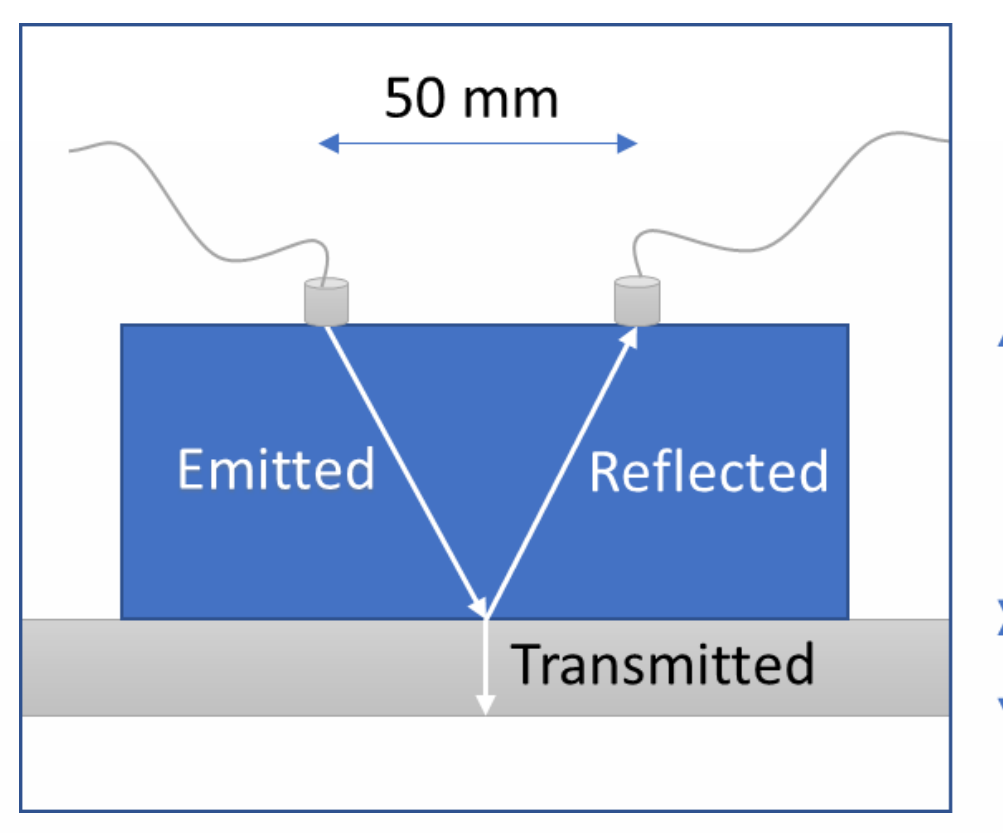

$50 \mathrm{~mm}$ $22 \mathrm{~mm}$

$\rho=$ Density of materials

$V=$ Wave velocity 


\section{NON-DESTRUCTIVE TECHNIQUES}

\section{MMW SPECTROMETRY}

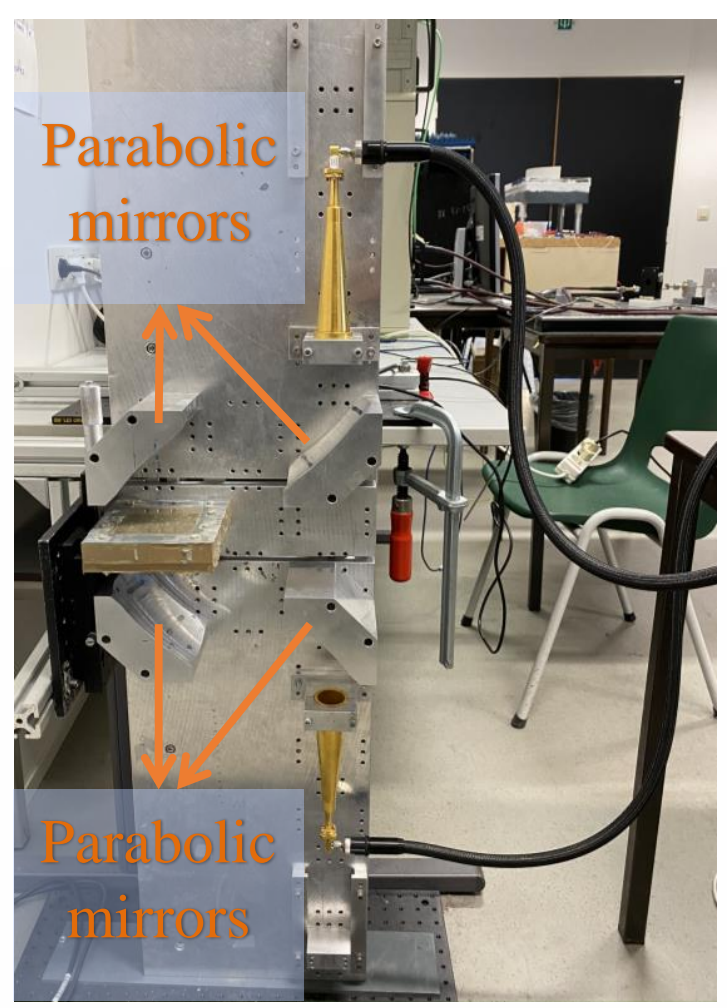

Electromagnetic technique based on sweeping frequencies in a determined bandwidth (between 30 and $300 \mathrm{GHz}$ ) through a sample. With the amplitude of the transmitted and reflected waves and known geometry, the EM properties can be determined.
Water (High permittivity)

$+$

Cement (Low permittivity)

$+$

Sand (Low permittivity)

$+$

Textiles (Low permittivity)

$=$

TRC (Low permittivity) 


\section{Results}

\section{(1I) MECHANICS OF MATERIALS \& CONSTRUCTIONS




\section{RESULTS}

\section{UPV}

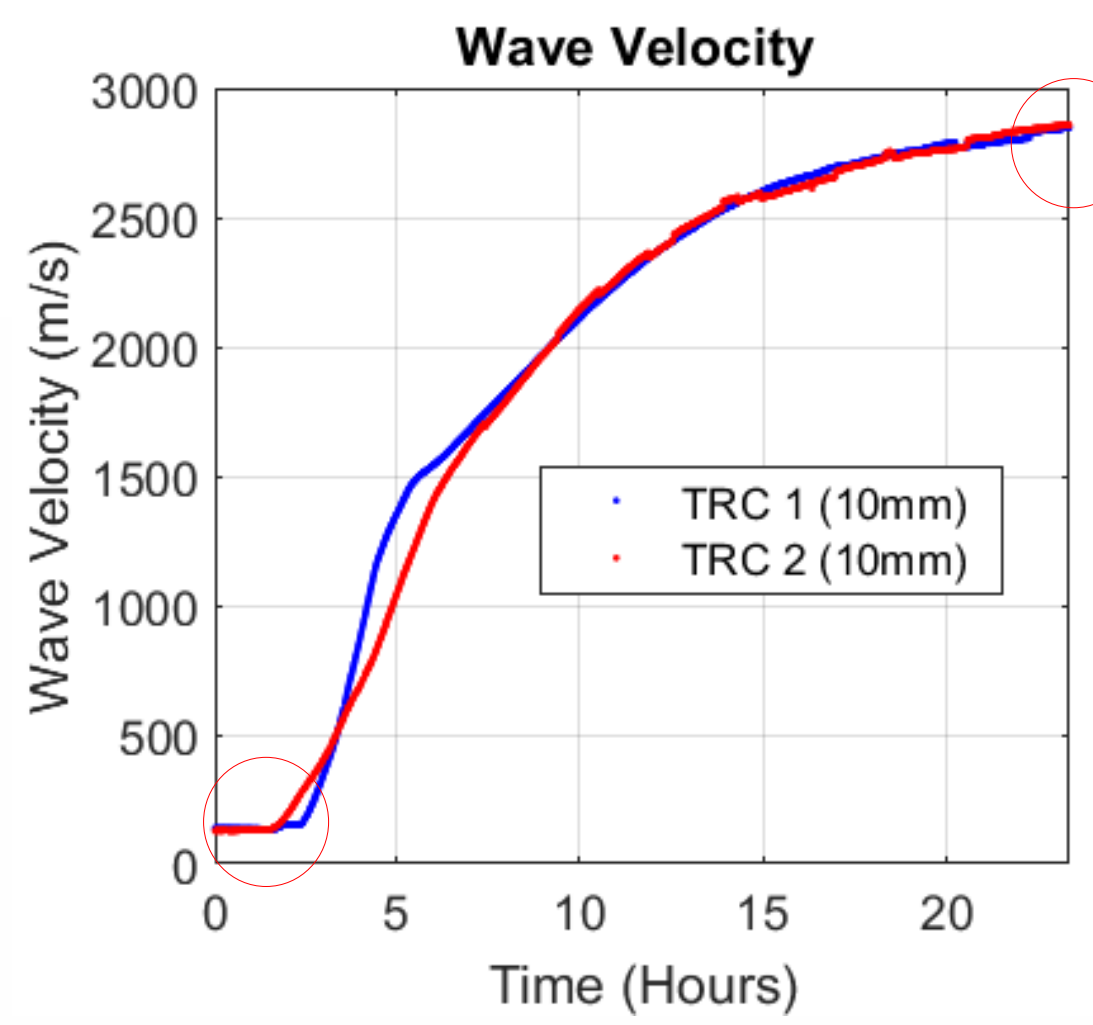

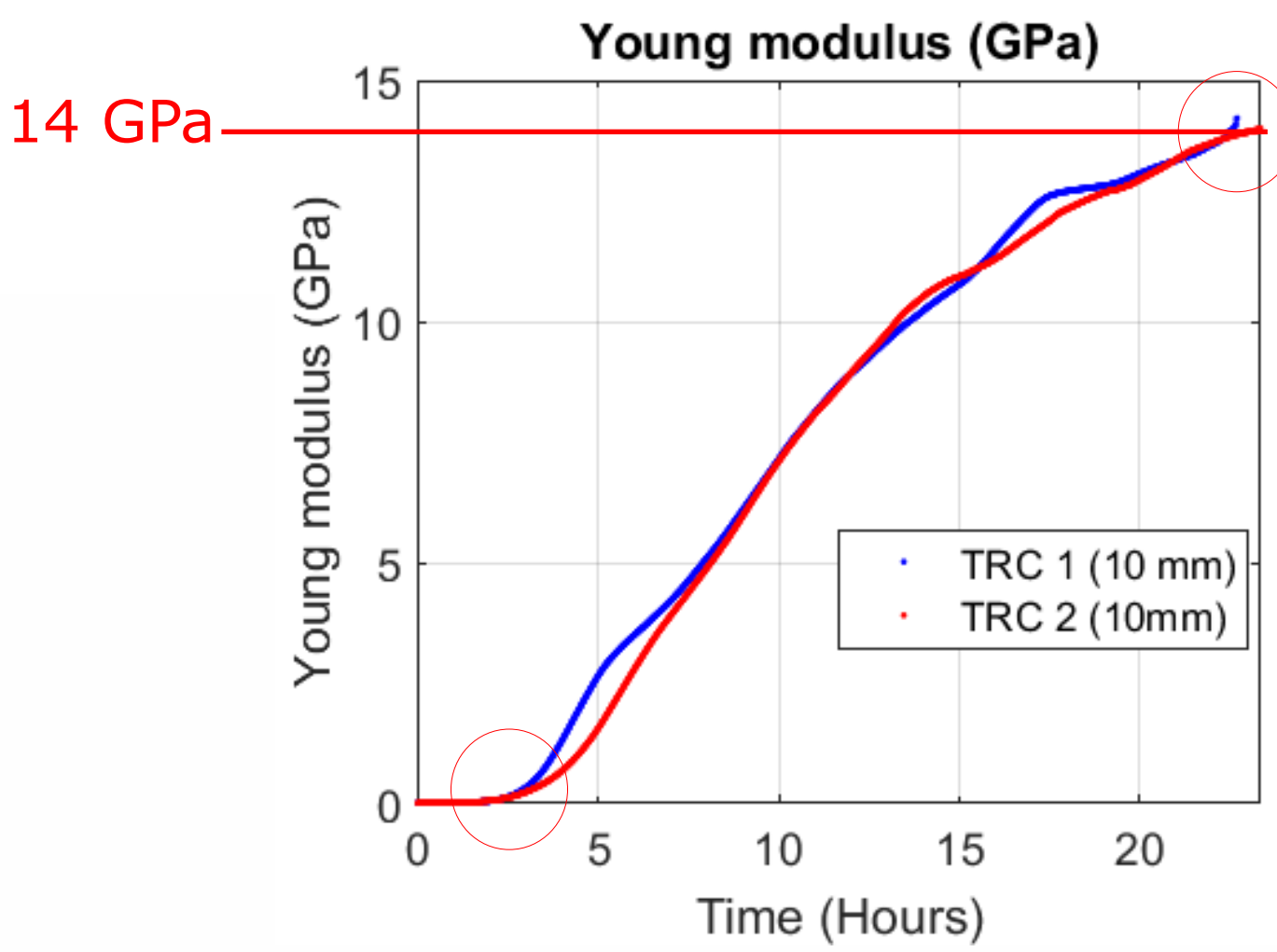




\section{RESULTS}

\section{UWR}

Reflection
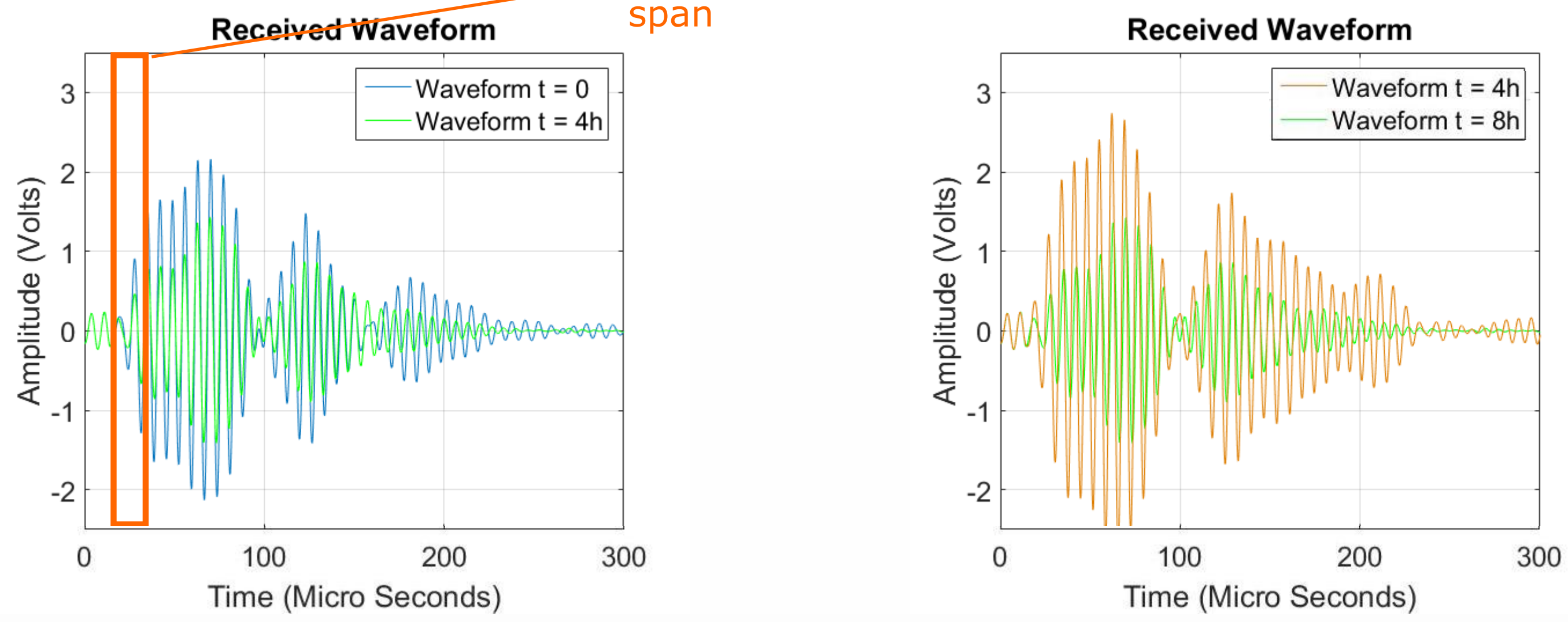


\section{RESULTS}

\section{UWR}

1. Hardening of surface of TRC

Minimum point - Theoretically

$$
\mathrm{Z1}=\mathbf{Z 2} \text {. }
$$

High sensitivity of the test

2. Low sensitivity of the test.

It is relative to the buffer material.

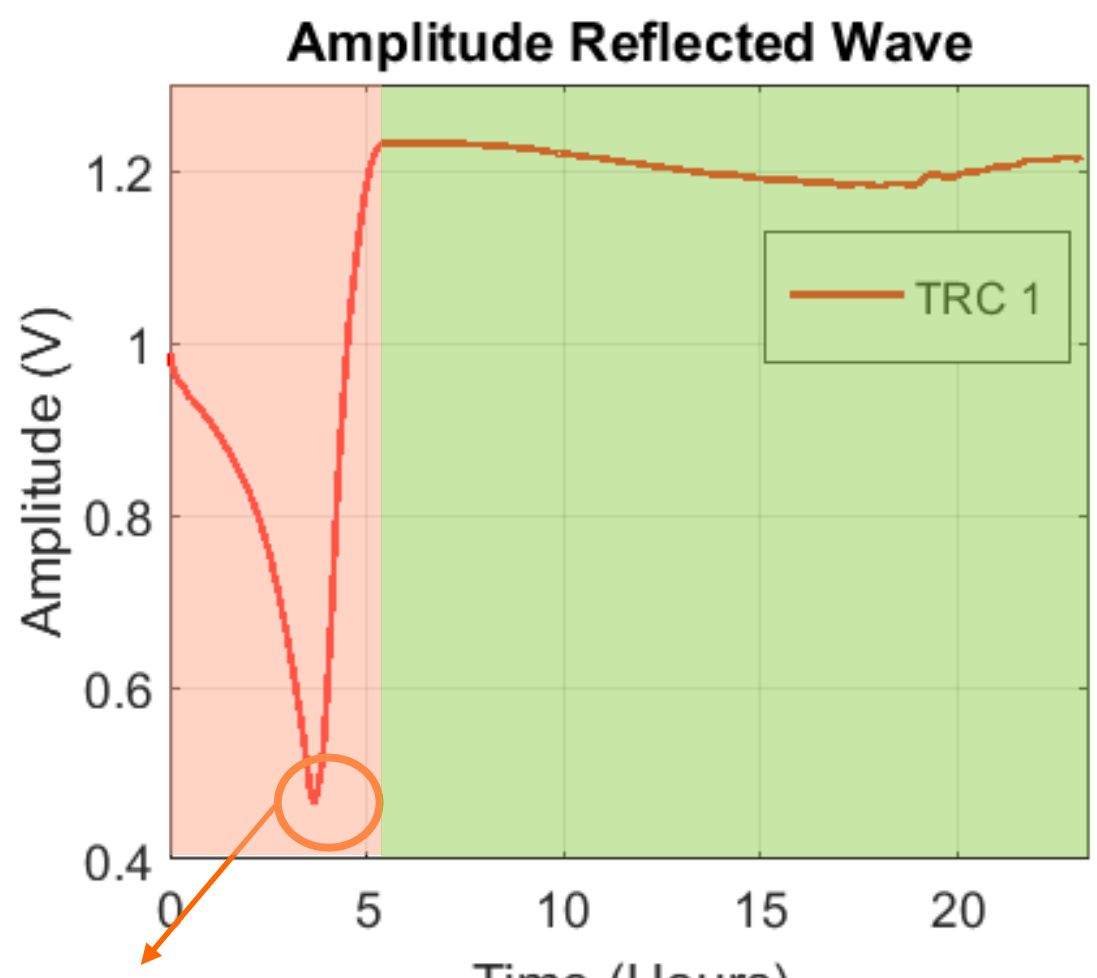

Minimum reflection $=0.47$ (Volts) Time (Hours)

Time $\min$ reflection $=219 \mathrm{~min}=3 \mathrm{~h} 39 \mathrm{~min}$

$$
E=4.47 \mathrm{GPa}
$$




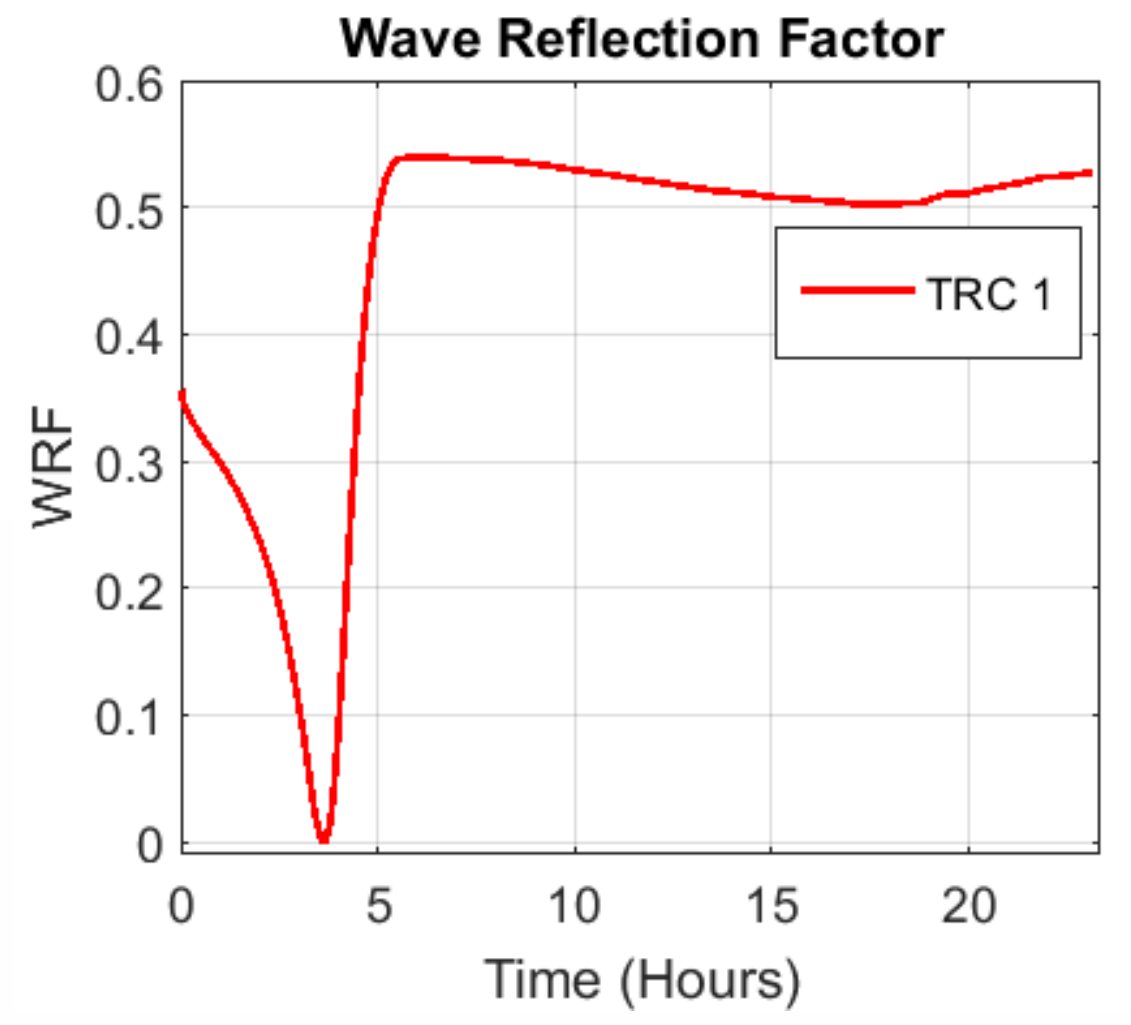

The amplitude monitored was normalized by dividing it vs air and subtracting the minimum reflection to 0 .

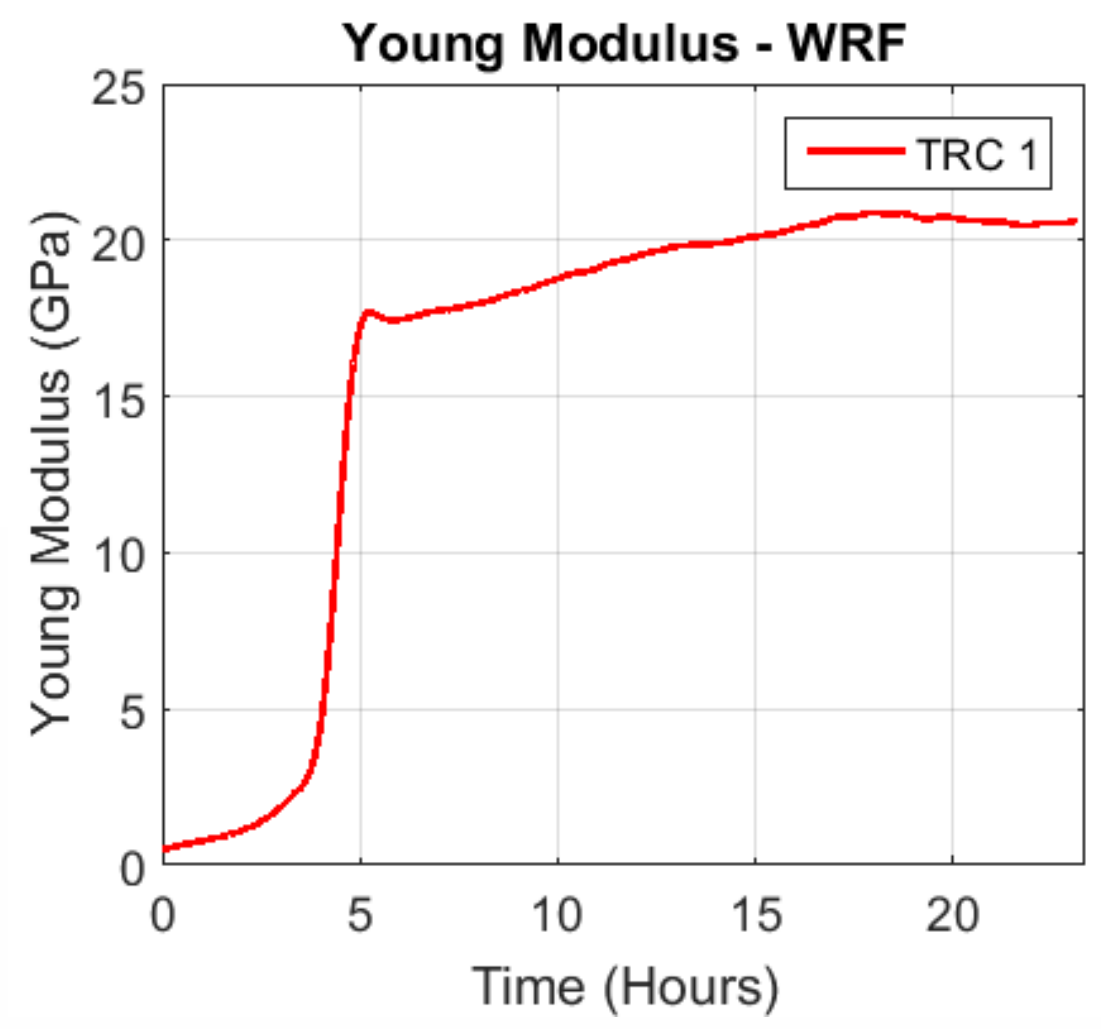

The Young modulus was calculated. 


\section{RESULTS}

\section{MMW SPECTROMETRY}

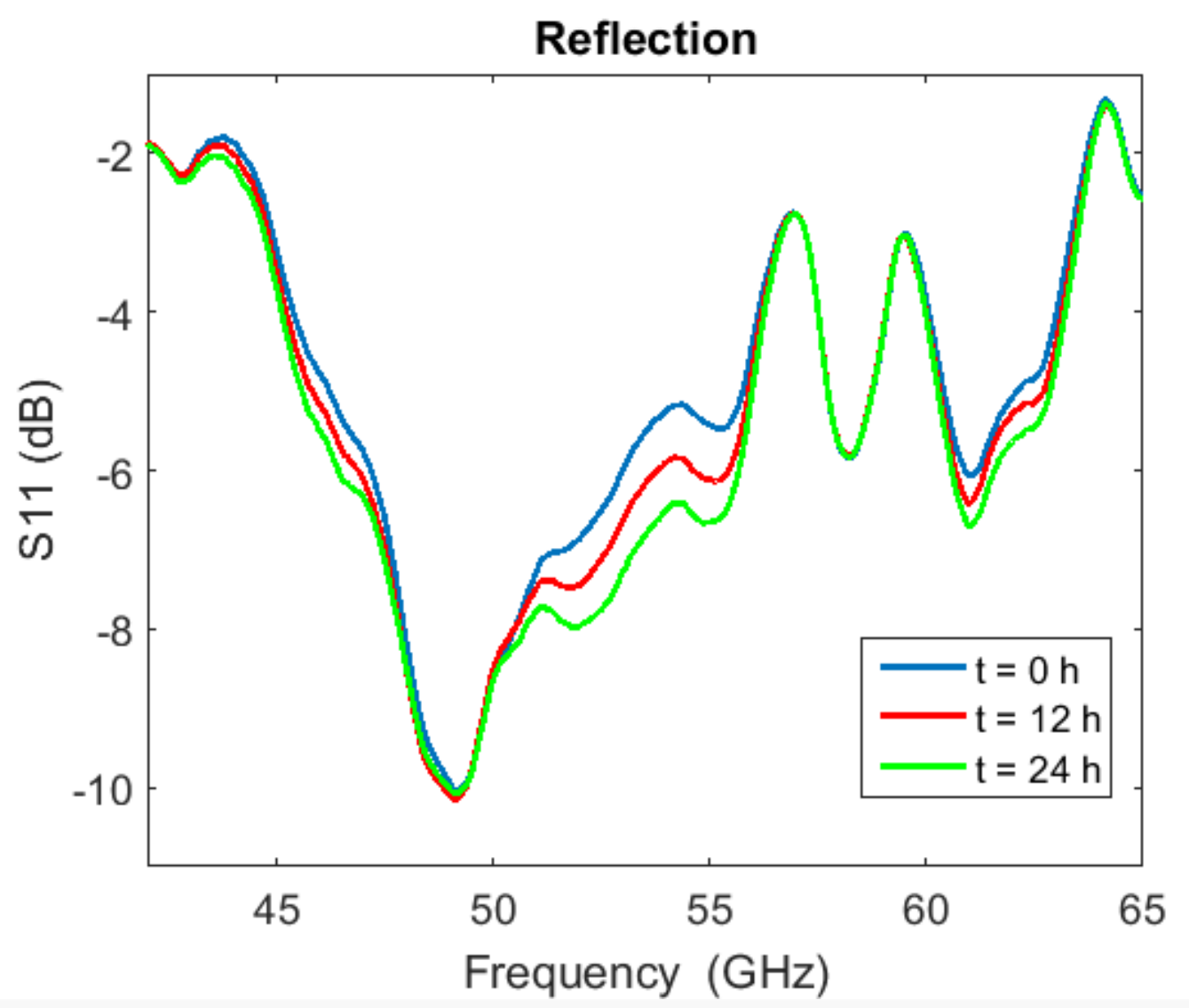

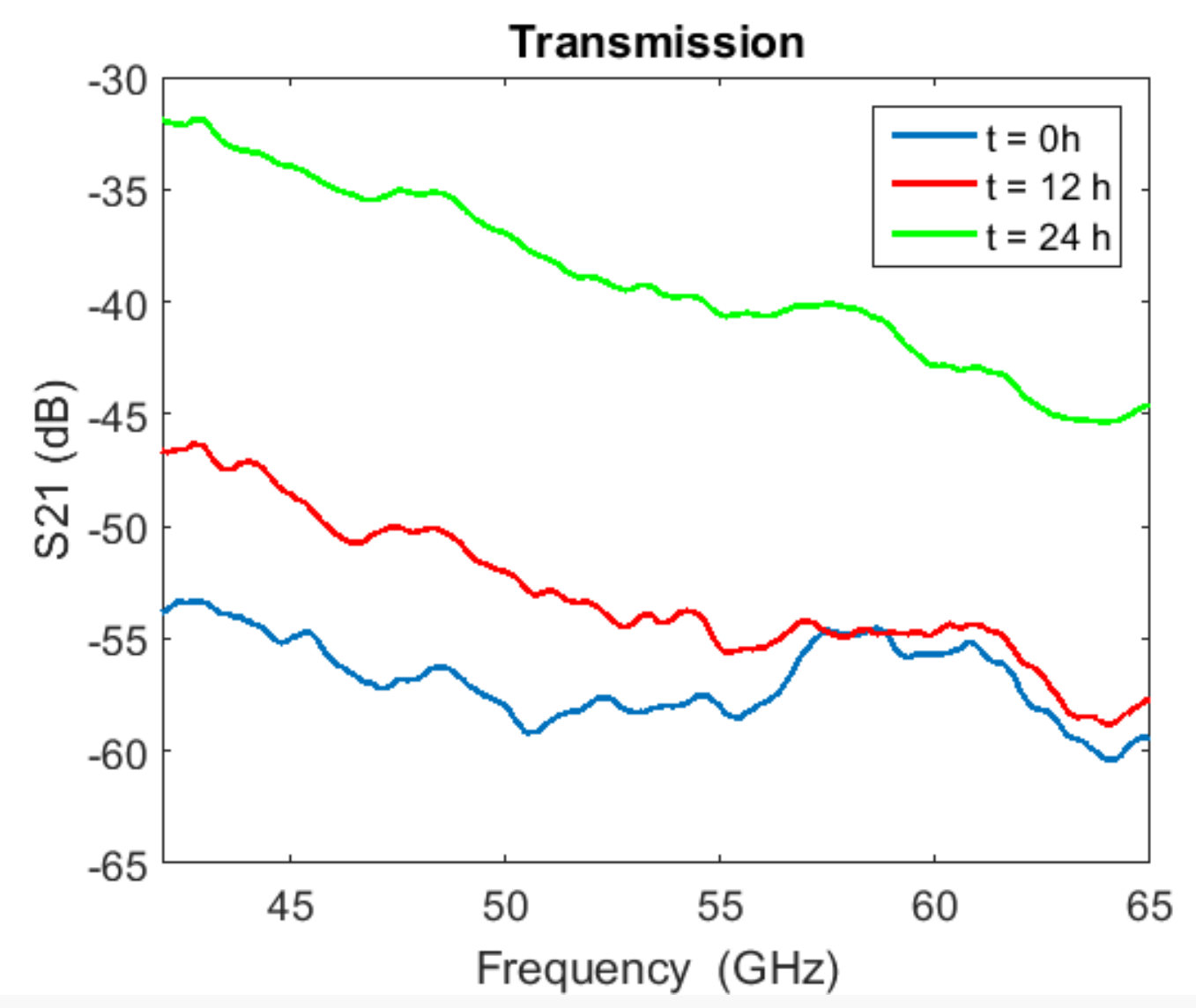




\section{MMW SPECTROMETRY - S21}

1. The wave passes through the sample of $10 \mathrm{~mm}$.

2. It can not pass through thicker samples (22 mm)

3. $47.5 \mathrm{GHz}$

4. Dormant period, or period in which the wave cannot pass through the sample

5. Reactions and higher EM wave transmission

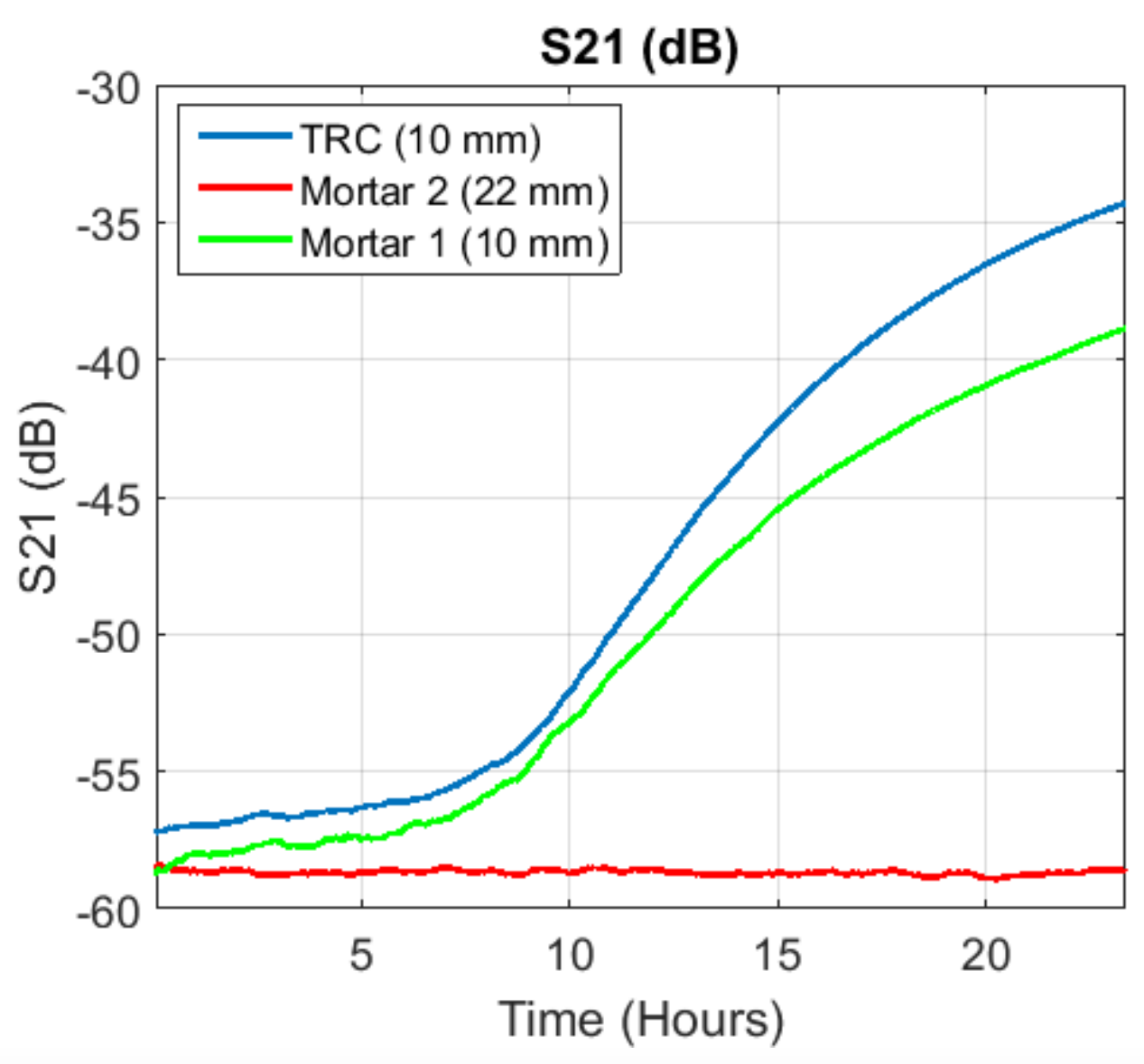




\section{COMPARISON MMW AND UPV 24H}

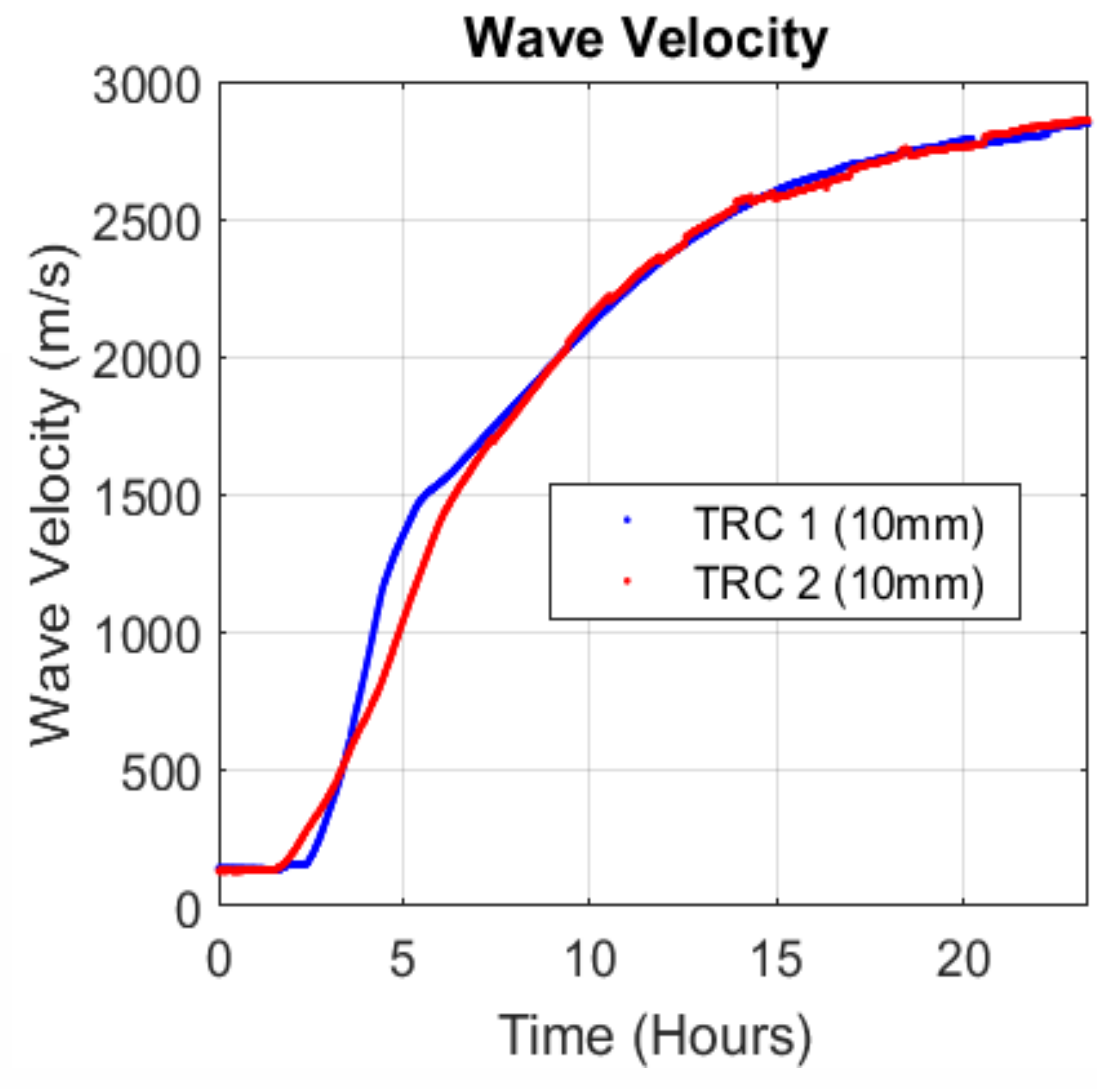

Development of strength

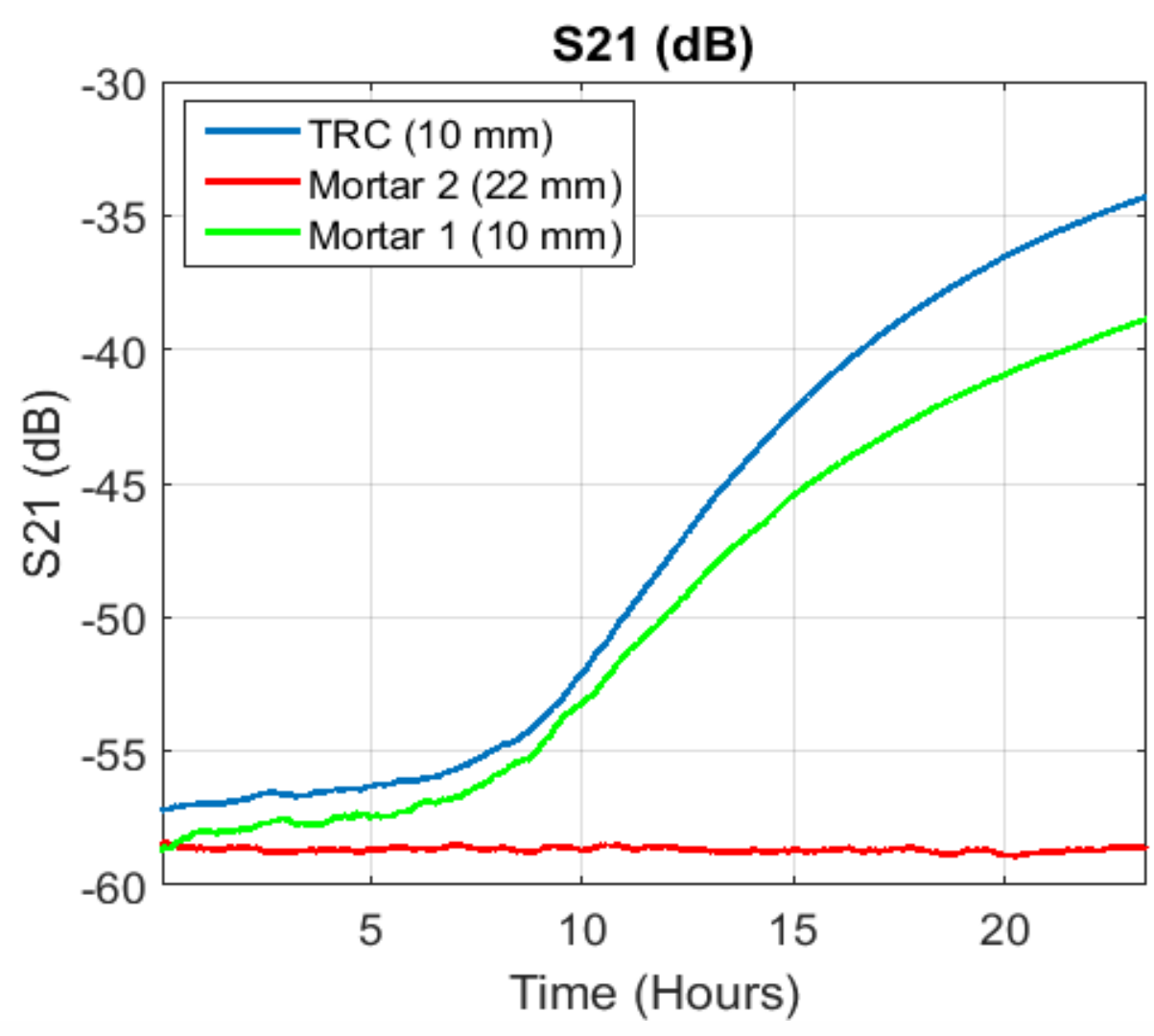

Reduction of free water $\&$ chemical reactions 


\section{Conclusions}

\section{(II) MECHANICS OF MATERIALS \& CONSTRUCTIONS




\section{GENERAL CONCLUSIONS}

- UPV can successfully monitor the development in stiffness of early age TRC, allowing for estimation of the Young's Modulus.

- When both sides of the sample are not accessible, UWR can be used as an alternative monitoring technique from where the stiffness of the surface of the material can be estimated. The BM can be chosen to match an indicative impedance.

- MMW in transmission shows sensitivity to chemical reactions involved in the hydration and curing of TRC and mortar specimens, allowing for monitoring during this stage. The sensitivity of MMW allows for differentiation between TRC and mortar. 


\section{ACKNOWLEDGMENTS}

The financial support of FWO (Fonds Wetenschappelijk Onderzoek-Vlaanderen) through grants G.0337.19N and $\mathbf{1 2 J 7 7 2 0 N}$ is gratefully acknowledged. The authors also acknowledge the Vrije Universiteit Brussel (VUB) through the SRP-project M3D2, the ETRO-IOF project and the OZR-3251 project, GHz-THz VNA measurement infrastructure, from benchtop to portable instruments. 


\section{Thank you}

Mail: nicolas.ospitia.patino@vub.be

\section{Manc \& CONSTRUCTIONS}

\section{ASEC \\ 2020}

